\title{
Karakteristik Ikan Tuna sirip biru selatan (Thunnus maccoyii) Hasil Tangkapan Kapal Rawai Tuna yang didaratkan di Pelabuhan Benoa
}

\author{
I Gede Adi Swastana ${ }^{a}$, Abd. Rahman As-syakur ${ }^{a *}$, Dian Novianto ${ }^{\mathrm{b}}$ \\ ${ }^{a}$ Program Studi Ilmu Kelautan, Fakultas Kelautan dan Perikanan, Universitas Udayana, Bukit Jimbaran, Bali 80361, Indonesia \\ ${ }^{b}$ Loka Penelitian Perikanan Tuna, Kementerian Kelautan dan Perikanan, Jalan Mertasari Nomor 140 Sidakarya, Denpasar, Bali 80224, Indonesia \\ * Penulis koresponden. Tel.: +62-361-702-802 \\ Alamate-mail: assyakur@unud.ac.id
}

Diterima (received) 22 Juli 2016; disetujui (accepted) 23 November 2016; tersedia secara online (available online) 3 Desember 2016

\begin{abstract}
Southern bluefin tuna (SBT) is scientifically known Thunnus maccoyii, and just live in the southern hemisphere. SBT fish classified as the most exploited tuna fish in the southeastern part of the Indian Ocean, so it is protected by the International Union for the Conservation of Nature (IUCN). The aim of this study is too collected of SBT fish caught during January which is the peak of SBT landing in Benoa port. The study was conducted base on data sampling, observation and interviews on 33 ships were landing SBT fish during January 2016. Based on observations from 33 vessels, we found that the total of SBT fish that landed in Benoa port during January 2016 is 251 fresh fish and 366 frozen fish. However just 251 SBT fresh fish were sampled, and the result indicated the fresh SBT fish is dominated by weigh between $61-70 \mathrm{~kg}$ with number 61 fish with a total weight of 19.28 tonne. The SBT were caught dominated by fish that has FL (fork lenght) ranging between $151-160 \mathrm{~cm}$ with number 69 fish. While the smallest SBT range between $131-140 \mathrm{~cm}$ with the number of 5 fish. These results indicate that SBT fish caught in the Souetheast Indian Ocean during January 2016 is generaly relative small fish (130-160 cm FL) with a number of 163 fish and mature SBT fish (FL $>162 \mathrm{~cm}$ ) with a number of 88 and young SBT $(\mathrm{FL}<130 \mathrm{~cm})$ with a number of 5 fish. Based on morphometric analysis, eyeball diameter of SBT range 6-8 cm, the length lateral head from the tip of the mouth to behind the gill cover ranging $46-54 \mathrm{~cm}$, the length of body from the early dorsal or in front of the first dorsal fin ranging between $38-47 \mathrm{~cm}$, the height of fish at the end of the anal or at the end ranging between $34-39 \mathrm{~cm}$, the high of caudal peduncle ranging between $4-5 \mathrm{~cm}$, th length of the dorsal base of the tail fish ranging between $53-63 \mathrm{~cm}$, and the length of the base of tail anal from anal to tail ranging between $41-51 \mathrm{~cm}$. Base on size and age composition, it is shown that the growth of SBT during January 2016 is isometric.
\end{abstract}

Keywords: Benoa harbor; Southern Bluefin Tuna; morphology; morphometrics

\begin{abstract}
Abstrak
Ikan tuna sirip biru selatan ini secara ilmiah dikenal Thunnus maccoyii, dan hanya hidup di belahan bumi selatan, maka secara umum dikenal Southern Blufin Tuna (SBT). Ikan SBT tergolong ikan yang paling besar dieksploitasi di bagian tenggara Samudera Hindia, sehingga dilindungi oleh International Union for the Conservation of Nature (IUCN). Tujuan dari penelitian ini adalah untuk pendataan hasil tangkapan ikan SBT saat bulan puncak pendaratan SBT di Pelabuhan Benoa, khususnya pada bulan Januari 2016. Penelitian dilakukan dengan cara sampling, observasi dan wawancara pada 33 unit kapal yang melakukan pendaratan ikan SBT selama Januari 2016. Berdasarkan hasil observasi dari 33 unit kapal, diperoleh bahwa total SBT yang didaratkan di Pelabuhan Benoa selama Januari 2016 adalah sebanyak 251 ekor ikan SBT segar dan 366 ikan SBT beku. Dari total 251 ikan SBT, hanya 151 ekor ikan SBT segar yang disampling dan didominasi oleh ikan yang beratnya berkisar antara 61-70 kg sebanyak 61 ekor dengan berat total 19.28 ton. Ikan SBT yang disampling didominasi oleh ikan yang ukuran panjangnya FL (fork lenght) berkisaran 151-160 cm sebanyak 69 ekor. Sedangkan yang terkecil berkisar antara 131-140 cm sebanyak 5 ekor. Hasil ini menunjukan bahwa ikan SBT yang tertangkap di Samudera Hindia pada bulan Januari 2016 pada umumnya relatif belum dewasa (FL 130-160 cm) dengan jumlah 145 ekor, ikan SBT dewasa $(\mathrm{FL}>162 \mathrm{~cm})$ berjumlah 101 ekor dan ikan SBT muda $(\mathrm{FL}<130 \mathrm{~cm})$ berjumlah 5 ekor. Berdasarkan analisis morfometrik ikan SBT yang didaratkan selama Januari 2016, terlihat bahwa diameter bola mata ikan SBT berkisar antara 6-8 cm, panjang kepala bagian lateral dari ujung mulut sampai di belakang tutup insang berkisar antara $46-54 \mathrm{~cm}$, tinggi badan di awal dorsal atau di depan sirip punggung yang pertama berkisar antara $38-47 \mathrm{~cm}$, tinggi badan di akhir anal atau di akhir berkisaran antara 34-39 $\mathrm{cm}$, tinggi batang ekor antara 4-5 cm, panjang pangkal ekor dorsal berkisar antara 53-63 cm, dan panjang pangkal ekor anal dari anal sampai ekor berkisar antara $41-51 \mathrm{~cm}$. Sementara itu, berdasarkan hubungan panjang dan berat, maka diketaui tipe pertumbuhan ikan SBT yang didaratkan di Pelabuhan Benoa selama Januari 2016 besifat isometrik.
\end{abstract}

Kata Kunci: Pelabuhan Benoa; ikan Tuna Sirip Biru Selatan; morfologi; morfometrik

\section{Pendahuluan}

Indonesia merupakan negara yang mempunyai potensi kelautan yang sangat besar dan produksi perikanan peringkat ke -13 terbesar di dunia (Ronny, 2011). Perairan Samudera Hindia di sebelah selatan Jawa, Bali, dan Nusa Tenggara merupakan daerah pemijahan dari beberapa jenis tuna. Ikan ini biasanya bermigrasi ke perairan selatan 
Jawa dan Bali (Novianto dan Nugraha, 2016). Ikan tuna termasuk kelompok ikan Scombrid fishes, Famili Scombridae, Subfamili Scombrinae, suku Thunini, genus Thunnus. Terdapat tujuh jenis tuna yang ada di dunia yaitu Albakor (Thunnus alalunga), Madidihang (Thunnus albacares), tuna sirip utara (Thunnus thymus), tuna sirip biru selatan (Thunnus maccoyii), tuna sirip hitam (Thunnus atlanticus), tuna abu-abu (Thunnus tonggol), dan tuna mata besar (Thunnus obesus) (Sulistyaningsih dkk., 2014).

Salah satu jenis ikan yang memiliki nilai ekonomi tinggi bagi Indonesia adalah ikan tuna sirip biru selatan atau yang dikenal dengan sebutan southern bluefin tuna (SBT). Ikan SBT hanya hidup di belahan bumi selatan, maka secara umum dikenal Southern Blufin Tuna (SBT). Ikan SBT tergolong ikan yang paling besar dieksploitasi di bagian tenggara Samudera Hindia. Bukti genetik menunjukan bahwa ikan SBT adalah populasi tunggal dengan daerah pemijahan ikan SBT tersendiri pada wilayah selatan Indonesia di Samudra Hindia bagian tenggara (Hartog, 2011; Nieblas et al., 2014). Gunn et al. (2008) menduga bahwa tempat pemijahan ikan SBT terletak pada lintang 10-20 LS (Lintang selatan) dan bujur 100-125 BT (Bujur timur). Masa pemijahan ikan SBT berlangsung kira-kira 6 bulan dari September - Maret tahun berikutnya.

Ikan SBT adalah jenis tuna besar, bisa berenang dengan cepat, beruaya sangat jauh (highly migratory), dan merupakan jenis ikan pelagis besar. Warna tubuh ikan SBT memiliki warna tersendiri dari warna jenis ikan tuna lainnya, yaitu pada punggung ikan memiliki warna biru tua agak kehitam-hitaman sedangkan bagian bawah atau perutnya memiliki warna putih terang tetapi agak keperakperakan. Daerah operasi penangkapan SBT di Indonesia umumnya berada di Wilayah Pengelolaan Perikanan Republik Indonesia (WPP-RI) 573, di sekitar perairan Samudera Hindia sebelah Selatan Jawa dan Bali (Rahmawati dkk., 2013).

Mengingat tingginya ekploitasi terhadap sumber daya SBT, menyebabkan jenis ikan ini semakin sulit ditemukan di wilayah pemijahannya, khususnya pada umur SBT dewasa. Saat ini, International Union for the Conservation of Nature (IUCN) telah memasukan ikan SBT dalam status spesies yang terancam punah (critically endangered) pada IUCN Red List of Threatened Species sejak tahun 1996. Berdasarkan kondisi tersebut, sejak tahun 2006 Commission for The Conservation of Southern Bluefin Tuna (CCSBT) telah menerapkan catch documentation scheme (CDS) untuk memonitor pendistribusi SBT secara global. Semua anggota dan cooperating non-member CCSBT harus mengimplementasikan CDS untuk mendokumentasikan jalur distribusi spesies ini mulai dari penangkapan hingga ke tangan konsumen (Rahmawati dkk., 2013).

Upaya pengelolaan dan konservasi sumber daya SBT sangat diperlukan untuk menjaga keberlangsungan industri perikanan SBT di Indonesia. Pengelolaan perikanan merupakan semua usaha yang dilakukan untuk mencapai kelangsungan produktivitas sumber daya hayati perairan. Untuk itu, perlu adanya suatu rangsangan ilmu pengetahuan. Langkah awal yang dapat dilakukan adalah melakukan identifikasi terhadap sumber daya hayati yang tersedia. Identifikasi adalah tugas untuk mencari dan mengenal ciri-ciri taksonomi individu yang beraneka ragam dan memasukkanya ke dalam suatu takson. Identifikasi berkaitan erat dengan ciri-ciri taksonomi dan akan menuntun sebuah sampel kedalam suatu urutan kunci identifikasi, sedangkan klasifikasi berhubungan dengan mengevaluasi sejumlah besar ciri-ciri (Mardlijah, 2008). Identifikasi terhadap ikan pelagis besar khususnya ikan tuna sangat penting dilakukan dari segi ilmiah, karena berguna sebagai sumber pengetahuan, penunjang dalam penelitian, perencanaan kebijakan selanjutnya serta bermanfaat dalam proses konservasi ikan SBT.

Indonesia memiliki beberapa pelabuhan pendaratan ikan salah satunya yaitu Pelabuhan Benoa Bali, yang lokasinya cukup dekat dengan daerah operasi penangkapan SBT. Selain Pelabuhan Benoa, ikan SBT juga didaratkan di Pelabuhan Perikanan Samudera Nizam Zachman Jakarta dan PPS Cilacap. Di pelabuhanpelabuhan tersebut terdapat banyak kapal penangkap ikan tuna yang biasanya beroperasi di daerah sekitaran Samudera Hindia di bawah selatan Jawa dan Bali. Kapal tersebut menangkap ikan menggunakan alat tangkap rawai tuna. Kapal - kapal tersebut mendarat di pelabuhan untuk melakukan bongkar muat kapal di perusahaan yang sudah tersedia disana. Di Pelabuhan Benoa, terdapat dua jenis bongkaran ikan SBT yaitu bongkaran ikan beku dan ikan segar. Pada tahun 2010 hasil tangkapan ikan SBT mencapai 97.469 ton, pada tahun 2011 mencapai 168.59 ton, pada tahun 2012 mencapai 364.657 ton, dan pada tahun 2013 mencapai 721.591 ton, hasil ini menunjukan dari setiap tahunnya terjadi peningkatan hasil tangkapan ikan SBT, hasil tangkapan tertinggi biasanya pada akhir tahun dan berlanjut sampai awal tahun berikutnya (Rahmawati dkk., 2013).

Dari semua hasil tangkap ikan tersebut perlu dilakukan pendataan hasil tangkapan ikan SBT untuk memantau sekaligus untuk mencatat hasil tangkapan dari nelayan sehingga didapatkan sebuah gambaran bagaimana hasil tangkapan nelayan pada bulan puncak tangkapan ikan SBT. Berdasarkan uraian tersebut, maka perlu dilakukan penelitian yang bertujuan untuk mengetahui panjang, berat dan morfometrik ikan SBT yang di daratkan di Pelabuhan Benoa, khususnya saat bulan Januari 2016 serta mengetahui ciri-ciri eksternal dari jenis ikan SBT yang di daratkan di Pelabuhan Benoa pada bulan Januari 2016.

\section{Metode Penelitian}

\subsection{Data}

Penelitian ini dilakukan selama satu bulan yaitu pada bulan Januari 2016 di Pelabuhan Benoa Bali. Metode yang digunakan dalam penelitian ini yaitu menggunakan metode sampling. Dalam penelitian ini, data yang dikumpulkan terdiri dari data primer dan data sekunder. Data primer adalah data yang diperoleh langsung dari subyek penelitian yaitu terkait dengan data-data ikan SBT yang didaratkan dan dibongkar di Pelabuhan Benoa, Bali. Sedangkan data sekunder adalah data yang diperoleh dari pihak lain atau dari penelitian sebelumnya (Azwar, 2010). 
Data primer dikumpulkan dengan cara sampling, observasi dan wawancara. Pengumpulan data primer dilakukan dengan simple random sampling dari kapalkapal yang mendaratkan ikan SBT di Pelabuhan Benoa. Observasi yaitu melakukan pengamatan dan pencatatan secara sistematis terhadap peristiwa yang diamati tanpa mengajukan pertanyaan (Triharyuni dan Prisantoso, 2012).Adapun wawancara adalah cara pengumpulan data dengan tanya jawab sepihak dan berlandaskan pada tujuan penelitian (Setyadji dan Nugraha, 2012). Data yang diperoleh dengan sampling dan observasi antara lain informasi dan ukuran mengenai jenis ikan, morfologi ikan, klasifikasi ikan dan morfometrik. Pada penelitian ini, terdapat dua jenis data bongkaran ikan SBT yang sampling dan diobservasi yaitu bongkaran ikan beku dan ikan segar. Akan tetapi jenis bongkaran ikan beku hanya diketahui data-data berupa jumlah dan berat ikan SBT, sedangkan dari kan segar diketahui data-data berupa jumlah, berat, panjang serta morfometriknya. Sementara itu, data-data yang diperoleh melalui wawancara adalah jenis alat tangkap, lokasi tangkapan dan sistem penangkapan.

\subsection{Analisis}

\subsubsection{Identifikasi}

Pengidentifikasian dalam penelitian ini dimulai dengan menyiapkan alat dan bahan yang digunakan untuk melakukan identifikasi ikan SBT hasil tangkapan nelayan yang mendarat di Pelabuhan Benoa, Bali. Pengidentifikasian dilakukan untuk mengetahui morfometrik ikan SBT. Alat-alat yang digunakan antara lain kamera digital untuk mengambil gambar ikan hasil tangkapan, kaliper atau penggaris untuk mengukur panjang total tubuh ikan, meteran kain untuk mengukur lingkar dan tinggi tubuh ikan, bolpoint untuk mencatat hasil pengukuran. Sedangkan bahan yang diperlukan adalah ikan sampel dan buku yang digunakan untuk mencatat hasil identifikasi. Perusahaan ikan yang disampling sebanyak 11 perusahaan yang ada di Pelabuhan Benoa, diantaranya adalah PT. Perintis Jaya Internasional, PT. Jaya Kota, PT. Bali Nusa Windu Mas, PT. Intan Mas, PT. Bandar Nelayan, PT. Chiu Shih, PT. Daya Bahari Nusantara, PT. Hentry Jaya, PT. Bali Mina Mandiri, PT. Super Satu Bali, PT. Bali Tuna Segar. Untuk kapal yang diamati atau disampling hasil tangkapannya adalah kapal rawai tuna sebanyak 33 unit kapal.

Pengidentifikasian dilakukan dengan mengambil foto menggunakan kamera digital dan/atau lainnya, kemudian diamati ciri-ciri khusus pada ikan untuk mengetahui jenisnya. Penimbangan untuk berat ikan SBT dilakukan ditempat bersamaan dengan pedagang. Data yang diperoleh adalah nama ikan dan jumlah hasil tangkapan $(\mathrm{kg})$, panjang $(\mathrm{cm})$, morfometrik, yang kemudian dicatat. Pengidentifikasian ikan SBT dilakukan untuk mengetahui jenis ikan yang didaratkan oleh nelayan kapal rawai tuna dengan mengamati ciri-ciri khusus pada ikan hasil tangkapan nelayan yang didaratkan di Pelabuhan Benoa, Bali.

\subsubsection{Hubungan panjang dan Bobot}

Bobot dapat dianggap sebagai suatu fungsi dari panjang. Hubungan panjang-bobot hampir mengikuti hukum kubik yaitu bahwa bobot ikan sebagai pangkat tiga. Namun sebenarnya tidak demikian karena bentuk dan panjang ikan berbeda-beda sehingga untuk menganalisis hubungan panjang-bobot masing- masing spesies ikan SBT digunakan rumus yang umum sebagai berikut (Fadhil dkk., 2016) :

$W=a \times F L^{b}$

Dimana $\mathrm{W}$ adalah bobot ikan (kg), FL adalah panjang ikan SBT $(\mathrm{cm})$, serta a dan b adalah konstanta regresi power. Untuk mendapatkan parameter konstanta a dan b, digunakan analisis regresi power sederhana dengan $\ln \mathrm{W}$ sebagai ' $y$ ' dan ln FL sebagai ' $x$ ', maka didapatkan persamaan regresi $\mathrm{y}=\mathrm{ax}{ }^{\mathrm{b}}$. Sedangkan untuk menguji nilai $\mathrm{b}=3$ atau $\mathrm{b} \neq 3$ dilakukan uji-t (uji parsial), dengan hipotesis $\mathrm{H} 0: \mathrm{b}=3$, hubungan panjang dengan bobot adalah isometrik; $\mathrm{H} 1: \mathrm{b} \neq 3$, hubungan panjang dengan bobot adalah allometrik, dimana allometrik positif jika b>3 (pertambahan bobot lebih cepat daripada pertambahan panjang), dan allometrik negatif jika $b<3$ (pertambahan panjang lebih cepat daripada pertambahan bobot).

\section{Hasil dan Pembahasan}

\subsection{Panjang baku ikan SBT}

Jumlah kapal rawai tuna yang sandar dan mendaratkan hasil tangkapan ikan SBT selama bulan Januari 2016 adalah sebanyak 33 unit kapal, sedangkan pada penelitian ini total kapal yang disampling sebanyak 33 unit kapal, tetapi tidak semua ikan SBT yang didaratkan disampling karena jumlahnya yang cukup banyak. Sebagian besar kapal yang mendaratkan hasil tangkapannya adalah kapal penampung dimana kapal-kapal tersebut mendaratkan hasil tangkapan berupa ikan beku dan ikan segar. Mengingat data panjang ikan SBT hanya diperoleh dari data ikan segar, maka sub-bab ini hanya menampilkan data dari hasil tangkapan ikan SBT segar.

Dari hasil sampling yang lakukan di lapangan selama 21 hari, didapatkan hasil berupa panjang FL (fork lenght) minimum ikan SBT yang didaratkan di Pelabuhan Benoa selama Januari 2016 adalah $128 \mathrm{~cm}$ dan panjang FL maksimum mencapai $185 \mathrm{~cm}$. Berdasarkan Gambar 1, terlihat bahwa panjang rata-rata ikan SBT yang tertangkap didominasi oleh ikan yang ukuran panjang FL berkisar antara 151-160 cm sebanyak 69 ekor dari jumlah sampling ikan SBT segar yang dilakukan sebanyak 251 ekor. Sedangkan yang terkecil berkisaran 121-130 cm sebanyak 5 ekor. Panjang rata-rata ikan SBT yang tertangkap yaitu $156.381 \mathrm{~cm}$. Hasil ini menunjukan bahwa ikan SBT yang tertangkap di Samudera Hindia pada Januari 2016 pada umumnya relatif tidak besar. Menurut Bestley et al. (2009), ikan SBT yang memiliki panjang $159.7 \mathrm{~cm}$ dengan berat 79.1 berumur sekitar 9 tahun. Berdasarkan hubungan FL dengan umur ikan SBT, maka ikan SBT yang didaratkan selama Januari 2016 memiliki umur 
dengan rentang 4 sampai 34 tahun (Gunn et al., 2008), dimana FL ikan SBT > $162 \mathrm{~cm}$ merupakan ikan SBT yang sudah dianggap dewasa (Evans et al., 2012). Selain itu, dari total ikan segar yang didaratkan, hanya 88 ekor atau $35,06 \%$ ikan SBT yang sudah mencapai usian dewasa yang didaratkan di Pelabuhan Benoa selama Januari 2016.

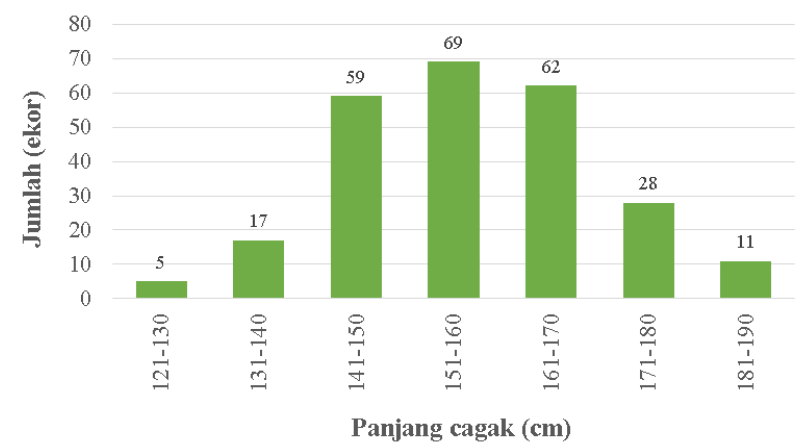

Gambar 1. Distribusi panjang FL ikan SBT yang didaratkan di Pelabuhan Benoa selama Januari 2016.

Farley et al. (2014) menduga tempat pemijahan ikan SBT yang terletak di lintang $10^{\circ}-20^{\circ}$ LS dan bujur $100^{\circ}$ $125^{\circ} \mathrm{BT}$ adalah sumber ikan SBT yang ditangkap dan didaratkan di Pelabuhan Benoa. Periode pemijahan ikan SBT berlangsung kira-kira enam bulan dari bulan September sampai April tahun berikutnya. Akan tetapi, wilayah dan periode reproduksi bisa bergeser sedikit dari tahun ke tahun karena perubahan kondisi oseanografi.

Dugaan tempat pemijahan ikan SBT ini didasarkan pada hasil penelitian Nieblas et al. (2014) dari ikan juvenilnya yang di tangkap dan perkembangan gonadnya dari ikan SBT ini yang ditangkap dengan rawai tuna. Selanjutnya dia menemukan ikan juvenil SBT dengan panjang yang ditangkap antara 3-8 $\mathrm{mm}$, dan panjang ikan SBT di tempat pemijahan ini didominasi oleh ukuran 160 $\mathrm{cm}$ yang gonadnya sudah matang.

Dari hasil pengamatan perkembangan gonad dan panjang diketahui bahwa ikan SBT mencapai usia matang pada panjang $130 \mathrm{~cm}$. Panjang ikan SBT demikian itu diperkirakan berumur antara 6 hingga 7 tahun (Farley et al., 2014). Ikan SBT ini bergerak musiman mengikuti arus angin ini ke timur Australia, ke timur selandia baru, dan lepas pantai Afrika Selatan. Ikan SBT yang tumbuh dewasa akan kembali keperairan asalnya pada bulan September-Maret untuk memijah di perairan selatan Jawa, Bali, dan Nusa Tenggara. Dan daur hidup yang sama akan terulang kembali (homing behavior) pada tahun berikutnya.

\subsection{Bobot ikan SBT}

Berat ikan SBT diperoleh dari data bongkaran ikan beku dan ikan segar di Pelabuhan Benoa. Jumlah total ikan SBT segar dan beku yang didaratkan di Pelabuhan Benoa selama Januari 2016 mencapai 617 ekor dengan berat minimum ikan segar adalah $31 \mathrm{~kg}$ dan berat minimum ikan beku adalah $13 \mathrm{~kg}$. sementara itu berat maksimum ikan segar yang didaratkan mencapai $157 \mathrm{~kg}$ dan berat maksimum ikan beku mencapai $140 \mathrm{~kg}$. Berdasarkan hasil sampling didapatkan bahwa sebaran bobot ikan SBT yang didaratkan oleh kapal rawai tuna dari perairan Samudra Hindia memiliki bobot rata-rata $76,8 \mathrm{~kg}$.

Berdasarkan distribusi berat ikan SBT segar, kelompok berat $61-70 \mathrm{~kg}$ memiliki jumlah terbanyak yaitu mencapai 61 ekor dan terendah pada kelompok berat 121130 dan 151-160 kg dengan jumlah masing-masing 1 ekor serta tidak ada tangkapan pada kelompok berat 141-150 $\mathrm{kg}$ dari jumlah sampling yang dilakukan sebanyak 251 ekor (Gambar 2) dan total berat 19.28 ton. Sementara itu pada jenis bongkaran ikan SBT beku, kelompok berat 51$60 \mathrm{~kg}$ memiliki jumlah terbanyak yaitu mencapai 108 ekor dan disusul oleh kelompok berat 61-70 kg dengan jumlah 97 ekor. Adapun kelompok berat yang memiliki jumlah tangkapan paling sedikit adalah kelompok berat 111-120 $\mathrm{kg}$ dan 131-140 kg dengan jumlah masing-masing 2 ekor serta kelompok berat $121-130 \mathrm{~kg}$ dan 141-150 kg tidak memiliki tangkapan (Gambar 2).

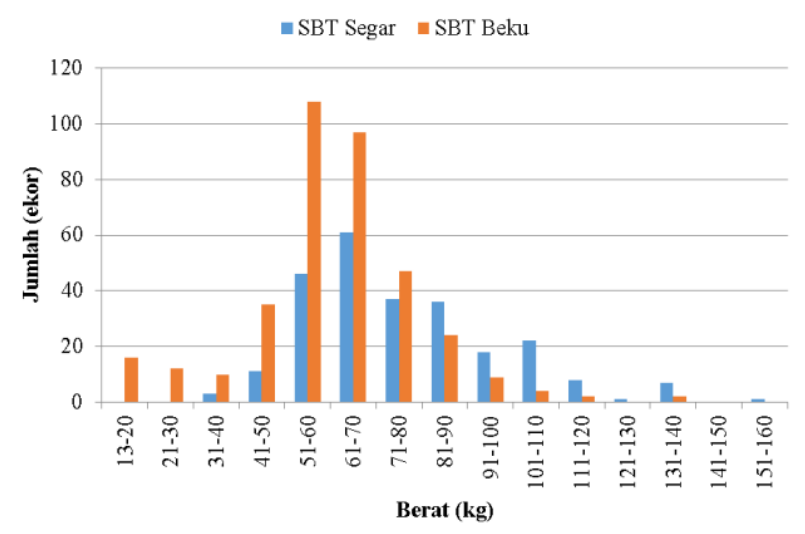

Gambar 2. Distribusi berat ikan SBT dalam keadaan segar dan beku yang dibongkar di Pelabuhan Benoa selama Januari 2016

Dari data Loka Penelitian Perikanan Tuna dari tahun 2010-2013 puncak tertinggi tangkapan terjadi selama 7 bulan yaitu pada bulan September sampai bulan Maret tahun berikutnya karena pada bulan tersebut ikan tuna jenis ini melakukan pemijahan di perairan selatan Jawa, Bali, dan Nusa Tenggara (Sulistyaningsih dkk., 2014). Bestley et al. (2009) mengatakan bahwa ikan SBT yang memiliki bobot $66.0 \mathrm{~kg}$ dengan panjang $150.1 \mathrm{~cm}$ berkisar berumur 8 tahun.

Menurut Gunn et al. (2008), ikan SBT mencapai usia matang pada berat $40 \mathrm{~kg}$ ke atas dengan perkiraan umur 67 tahun. Berdasarkan kondisi tersebut, masih terdapat 41 ekor $(6,65 \%)$ ikan SBT yang belum mencapai usia matang yang didaratkan di Palbuhan Benoa selama Januari 2016. Dimana bongkaran ikan SBT beku memiliki jumlah yang lebih banyak (38 ekor) dibandingkan dengan bongkaran ikan SBT segar (3 ekor). Maka dengan demikian ikan SBT yang tertangkap kebanyakan ikan yang sudah mencapai usia matang. Jumlah ikan SBT belum matang yang daratkan masih dibawah $10 \%$ sehingga tidak terlalu mempengaruhi siklus hidup ikan SBT. Akan tetapi bila terus terjadi maka keberlanjutan hasil tangkapan akan dapat mempengaruhi hasil tangkapan pada tahun-tahun yang akan dating. Selain itu, hasil tangkapan ikan SBT yang telah matang juga dapat mengindikasikan bahwa 
jumlah ikan di Samudra Hindia masih tergolong normal. Jika ikan tuna yang tertangkap masih belum matang maka ini menunjukan stok ikan tuna di daerah Samudra Hindia sudah menipis.

\subsection{Hubungan panjang dan bobot}

Hubungan panjang bobot digunakan untuk menduga pertumbuhan dari sumberdaya ikan SBT. Berdasarkan jumlah ikan contoh yang diperoleh selama penelitian, dilakukan analisis dengan 151 ekor ikan SBT segar. Grafik analisis hubungan panjang-bobot ikan SBT hasil tangkapan kapal rawai tuna yang di daratkan di Pelabuhan Benoa dapat dilihat pada Gambar 3.

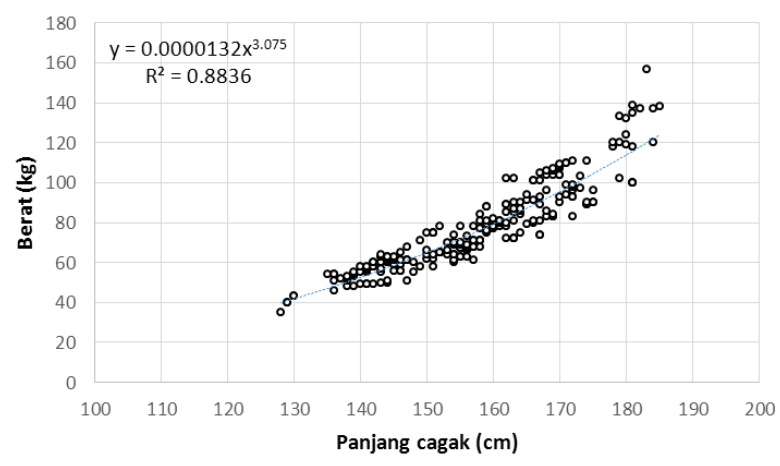

Gambar 3. Hubungan panjang bobot ikan SBT yang didaratkan di Pelabuhan Benoa selama Januari 2016.

Dari hasil perhitungan grafik pada Gambar 3 didapatkan persamaan hubungan panjang-berat ikan SBT adalah $\mathrm{W}=0.0000132 \mathrm{FL}^{3.075}$. Pada persamaan tersebut diperoleh nilai b yaitu 3.075 dan nilai a sebesar 0.0000132 dan nilai koefisien determinasi $\left(\mathrm{R}^{2}\right)$ sebesar 0.8836 dibulatkan menjadi 0.88 . Nilai koefisien determinasi tersebut berarti model dugaan mampu menjelaskan data sebesar $88,36 \%$.

Dari nilai $\mathrm{b}=3.075$ yang diperoleh dan setelah dilakukan uji $\mathrm{t}(\alpha=0.05)$ terhadap nilai $\mathrm{b}$, maka didapatkan bahwa nilai $b$ adalah sama dengan $3(b=3)$ yang berarti bahwa ikan SBT memiliki pola pertumbuhan isometrik. Dengan kata lain, laju pertumbuhan panjang ikan SBT di Samudera Hindia bagian perairan selatan Jawa, Bali, dan Nusa Tenggara selama Januari 2016 sama dengan laju pertumbuhan bobotnya. Hasil ini relatif berbeda dengan penelitian-penelitian sebelumnya seperti oleh Sulistyaningsih dkk. (2014) dan Shiao et al. (2008). Hasil studi Sulistyaningsih dkk. (2014) yang menggunakan hasil sampling ikan SBT pada Pelabuhan benoa selama Maret-September 2011 menunjukan tipe pertumbuhan ikan SBT yang bersifat alometrik negatif. Sedangkan hasil penelitian Shiao et al. (2008) yang menggunakan hasil tangkapan ikan SBT yang ditangkap di bagian selatan Samudera Hindia mengindikasikan bahwa bila ikan SBT yang ditangkap memiliki berat $<130$ $\mathrm{cm}$, maka tipe pertumbuhannya relatif berbentuk alometrik negatif dan cenderung isometrik yang menggambarkan pertambahan panjang lebih cepat dari pada pertambahan beratnya. Sementara itu dalam studi yang sama, Shiao et al. (2008) juga menemukan bahwa bila ikan SBT yang ditangkap memiliki berat $>130 \mathrm{~cm}$, maka tipe pertumbuhannya akan bersifat alometrik positif yang dapat menunjukan bahwa laju pertumbuhan bobot ikan SBT lebih besar dari laju pertumbuhan panjangnya. Perbedaan-perbedaan tersebut kemungkinan disebabkan oleh oleh jumlah sampel dan waktu pengambilan sampel yang tidak sama serta kondisi perairan di Samudra Hindia yang berbeda-beda setiap bulannya. Jumlah sampel, waktu dan kondisi Samudera Hindia saat pengukuran sangat berpengaruh terhadap pola hubungan panjang dan berat karena faktor cuaca yang tidak menentu menyebabkan ketersediaan makanan di perairan Samudera Hindia berbeda-beda sehingga ikan SBT mendapatkan asupan makanan yang berbeda-beda. Menurut Purwanto dkk. (2015), bahwa makanan ikan SBT biasanya meliputi Crutacea, Mollusca, Anthyphyta dan beberapa ikan pelagis kecil (Stolephorus spp. dan Sardinella spp.), dimana ketersedia makanan tersebut cukup melimpah di perairan Samudra Hindia, akan tetapi ketersediaanya sangat terpengaruh oleh kondisi oseanografi.

\subsection{Morfometrik ikan SBT}

Morfometri adalah suatu studi yang bersangkutan dengan variasi dan perubahan dalam bentuk (ukuran dan bentuk) dari organisme, meliputi pengukuran panjang dan analisis kerangka suatu organisme (Fadhil dkk., 2016). Studi morfometri didasarkan pada sekumpulan data pengukuran yang mewakili variasi bentuk dan ukuran ikan. (Dwivedi and Dubey, 2013; Ragionieri et al., 2019). Variasi morfometri suatu populasi pada kondisi geografi yang berbeda dapat disebabkan oleh perbedaan struktur genetik dan kondisi lingkungan (Balshaw et al., 2008). Oleh karena itu sebaran dan variasi morfometri yang muncul merupakan respon terhadap lingkungan fisik tempat hidup spesies tersebut. Dalam penelitian ini pengukuran morfometrik dilakukan hanya pada ikan yang tidak diekspor saja yang boleh diukur sedangkan yang ekspor tidak dapat diukur karena pada saat prosesing ikan langsung di kemas dan langsung dikirim ke luar negeri.

Dari hasil pengukuran morfometrik di lapangan didapatkan ukuran diameter bola mata ikan SBT berkisaran antara $6-8 \mathrm{~cm}$. Untuk panjang kepala bagian lateral ikan SBT yaitu pngukurannya dari ujung mulut sampai di blakang tutup insang didapatkan panjang berkisaran antara $46-54 \mathrm{~cm}$. Tinggi badan ikan SBT di awal sirip punggung pertama (dorsal) atau di depan sirip punggung yang pertama didapatkan panjangnya berkisaran antara $38-47 \mathrm{~cm}$. Tinggi badan ikan SBT di akhir sirip anus (anal) berkisaran antara $34-39 \mathrm{~cm}$. Tinggi batang ekor ikan SBT berkisaran antara 4-5 cm. Panjang dari pangkal ekor sampai sirip punggung (dorsal) ikan SBT berkisaran antara 53-63 cm. Panjang pangkal ekor anal ikan SBT yaitu pengukuran dari pangkal ekor sampai sirip anus (anal) atau sebaliknya didapatkan panjangnya berkisaran antara $41-51 \mathrm{~cm}$.

\section{Simpulan}

Studi mengenai komposisi hasil tangkapan ikan SBT yang mendarat di Pelabuhan Benoa selama Januari 2016 telah dilakukan. Data yang digunakan adalah berdasarkan hasil 
tangkapan dari 33 kapal yang mendaratkan ikan SBT di Pelabuhan Benoa. Identifikasi komposisi dilakukan dengan cara sampling, observasi dan wawancara. Dari hasil studi yang dilakukan didapatkan berat ikan SBT yang tertangkap selama bulan Januari 2016 didominasi oleh ikan yang beratnya berkisaran $61-70 \mathrm{~kg}$ sebanyak 61 ekor. Sedangkan panjangnya didominasi oleh ikan yang ukuran panjangnya (Fork Length) berkisaran 151-160 cm sebanyak 69 ekor. Hal ini menunjukan ikan yang tertangkap relatif masih belum dewasa. Ikan SBT hasil tangkapan kapal rawai tuna yang didaratkan di Pelabuhan Benoa memiliki bentuk badan yang bulat seperti torpedo, warna punggungnya biru kehitaman dan perutnya berwarna putih keperak-perakan, bentuk mulut superior, warna finletnya kuning bertepi hitam dan pada ujungnya berwarna putih, warna keelnya kuning pucat, memiliki 2 sirip punggung, sepasang sirip dada, sepasang sirip perut, satu sirip dubur, serta bentuk ekor lunate. Berdasarkan hubungan panjang dan berat, maka diketaui tipe pertumbuhan ikan SBT yang didaratkan di Pelabuhan Benoa selama Januari 2016 besifat isometrik.

\section{Daftar Pustaka}

Azwar, S. (2010). Metode penelitian. Yogyakarta, Indonesia: Pustaka Pelajar.

Balshaw, S., Edwards, J. W., Ross, K. E., Ellis, D., Padula, D. J., \& Daughtry, B. J. (2008). Empirical models to identify mechanisms driving reductions in tissue mercury concentration during culture of farmed southern bluefin tuna Thunnnus maccoyii. Marine pollution bulletin, 56(12), 20092017.

Bestley, S., Gunn, J. S., \& Hindell, M. A. (2009). Plasticity in vertical behaviour of migrating juvenile southern bluefin tuna (Thunnus maccoyii) in relation to oceanography of the south Indian Ocean. Fisheries Oceanography, 18(4), 237-254.

Dwivedi, A. K., \& Dubey, V. K. (2013). RETRACTED ARTICLE: Advancements in morphometric differentiation: a review on stock identification among fish populations. Reviews in Fish Biology and Fisheries, 23(1), 23-39.

Evans, K., Patterson, T. A., Reid, H., \& Harley, S. J. (2012). Reproductive schedules in southern bluefin tuna: are current assumptions appropriate? PloS one, 7(4), e34550.

Fadhil, R., Muchlisin, Z. A., \& Sari, W. (2016). Hubungan panjang-bobotdan morfometrik ikan Julung-julung (Zenarchopterus dispar) dari perairan Pantai Utara Aceh. Jurnal Ilmiah Mahasiswa Kelautan Perikanan Unsyiah, 1(1), 146-159.

Farley, J. H., Eveson, J. P., Davis, T. L., Andamari, R., Proctor, C. H., Nugraha, B., \& Davies, C. R. (2014). Demographic structure, sex ratio and growth rates of southern bluefin tuna (Thunnus maccoyii) on the spawning ground. PloS one, 9(5), e96392.

Gunn, J. S., Clear, N. P., Carter, T. I., Rees, A. J., Stanley, C. A., Farley, J. H., \& Kalish, J. M. (2008). Age and growth in southern bluefin tuna, Thunnus maccoyii (Castelnau): direct estimation from otoliths, scales and vertebrae. Fisheries Research, 92(2), 207-220.

Hartog, J. R., Hobday, A. J., Matear, R., \& Feng, M. (2011). Habitat overlap between southern bluefin tuna and yellowfin tuna in the east coast longline fishery-implications for present and future spatial management. Deep Sea Research Part II: Topical Studies in Oceanography, 58(5), 746-752.

Jatmiko, I., Nugraha, B., \& Satria, F. (2015). Capaian perkembangan program pemantau pada perikanan rawai tuna di Indonesia. Marine Fisheries: Jurnal Teknologi dan Manajemen Perikanan Laut, 6(1), 23-31.

Mardlijah, A. S. (2008). Analisis isi lambung ikan cakalang (Katsuwonus pelamis) dan ikan madidihang (Thunnus albacares) yang didaratkan di Bitung, Sulawesi Utara. Jurnal penelitian perikanan indonesia, 14(2), 227-235.

Nieblas, A. E., Demarcq, H., Drushka, K., Sloyan, B., \& Bonhommeau, S. (2014). Front variability and surface ocean features of the presumed southern bluefin tuna spawning grounds in the tropical southeast Indian Ocean. Deep Sea Research Part II: Topical Studies in Oceanography, 107, 64 76.

Novianto, D., \& Nugraha, B. (2016). Komposisi hasil tangkapan sampingan dan ikan target perikanan rawai tuna bagian timur Samudera Hindia. Marine Fisheries: Jurnal Teknologi dan Manajemen Perikanan Laut, 5(2), 119-127.

Purwanto, P., Sadiyah, L., \& Satria, F. (2015). Model pengendalian output penangkapan untuk penyesuaian terhadap kuota nasional tuna sirip biru selatan. Jurnal Kebijakan Perikanan Indonesia, 7(2), 103-114.

Ragionieri, L., Fratini, S., Vannini, M., \& Schubart, C. D. (2009). Phylogenetic and morphometric differentiation reveal geographic radiation and pseudo-cryptic speciation in a mangrove crab from the Indo-West Pacific. Molecular Phylogenetics and Evolution, 52(3), 825-834.

Rahmawati, N. T., Wisudo, S. H., Wiyono, E. S., \& Nurani, T. W. (2013). Dinamika perikanan tuna long line Indonesia (studi kasus tuna sirip biru selatan). Jurnal Teknologi Perikanan dan Kelautan, 4(2), 99-108.

Ronny, (2011). Tingkat Konsumsi Ikan: Peluang, Hambatan dan Strategi. Warta pasar ikan, 14, 1-2.

Setyadji, B., \& Nugraha, B. (2012). Hasil tangkap sampingan (HTS) kapal rawai tuna di Samudera Hindia yang berbasis di benoa. Jurnal Penelitian Perikanan Indonesia, 18(1), 43-51.

Shiao, J-C., Chang, S-K., Lin, Y-T., \& Tzeng, W-N. (2008). Size and age composition of southern bluefin tuna (Thunnus maccoyii) in the central Indian Ocean inferred from fisheries and otolith data. Zoological studies, 47(2), 158-171.

Sulistyaningsih, R. K., Wujdi, A., \& Nugraha, B. (2014). Distribusi panjang dan estimasi total tangkapan tuna sirip biru selatan (Thunnus maccoyii) pada musim pemijahan di Samudera Hindia. Jurnal Penelitian Perikanan Indonesia, 20(4), 215-224.

Triharyuni, S., \& Prisantoso, B. I. (2012). Species and size composition of tuna longline catches in the Southes of Java, Indian ocean. Jurnal saintek perikanan, 8(1), 52-58.

(C) 2016 by the authors; licensee Udayana University, Indonesia. This article is an open access article distributed under the terms and conditions of the Creative Commons Attribution license (http://creativecommons.org/licenses/by/3.0/). 